\title{
Executive functioning in Body Dysmorphic Disorder and Obsessive-Compulsive Disorder
}

\author{
Long Long Chen ${ }^{1}$, Oskar Flygare ${ }^{1}$, John Wallert ${ }^{1}$, Jesper Enander ${ }^{1}$, Volen Z. Ivanov ${ }^{1}$, Christian Rück ${ }^{1}$,
} Diana Djurfeldt ${ }^{1}$

1. Centre for Psychiatry Research, Department of Clinical Neuroscience, Karolinska Institutet, \& Stockholm Health Care Services, Stockholm County Council, Karolinska University Hospital, SE-14186 Huddinge, Sweden

\section{ABSTRACT}

Objective: To assess executive functions in patients with Body Dysmorphic Disorder (BDD) and Obsessive-Compulsive Disorder (OCD) compared with healthy controls.

Methods: Adults diagnosed with BDD $(n=26)$ or OCD $(n=29)$ according to DSM-5, and healthy controls $(n=28)$ underwent validated and computerized neuropsychological tests; spatial working memory (SWM), Intra- extra dimensional set shifting (IED) and Stop signal task (SST), from the Cambridge Neuropsychological Test Automated Battery (CANTAB). Test performance was compared between groups, and correlated to standardized symptom severity of BDD and OCD. Significance level was set to $\mathrm{p}<0.05$.

Results: There were no statistically significant between-group differences on key outcome measures in SWM, IED, or SST. There was a weak positive correlation between symptom severity and test errors on SWM and IED in both OCD and BDD groups; increased clinical severity were associated with more errors in these tests. Further, there was a negative correlation between symptom severity and SST in the BDD group.

Conclusions: Patients with BDD or OCD did not differ from healthy control subjects in terms of test performance, however there were several statistically significant correlations between symptom severity and performance in those with BDD or OCD. More studies on EF in BDD and OCD are required to elucidate if there are differences in EF between these two disorders. 
medRxiv preprint doi: https://doi.org/10.1101/2021.04.29.21256321; this version posted May 2, 2021. The copyright holder for this preprint

(which was not certified by peer review) is the author/funder, who has granted medRxiv a license to display the preprint in perpetuity.

All rights reserved. No reuse allowed without permission.

\section{INTRODUCTION}

Obsessive-Compulsive Disorder (OCD) and Body Dysmorphic Disorder (BDD) share characteristics such as intrusive thoughts and repetitive behaviors (1). Patients with OCD typically experience obsessional thoughts, images or impulses that cause anxiety or distress, which can be neutralized by overt compulsive behaviors or mental acts (2). Patients with BDD are preoccupied with a perceived defect in physical appearance and engage in repetitive excessive grooming, mirror checking or reassurance-seeking behaviors (3).

OCD and BDD share a number of important clinical features, including sex ratio, age of onset and treatment response to selective serotonin reuptake inhibitor (4). Moreover, evidence from a twin study supports a genetic overlap between OCD and BDD (5). Moreover, studies suggest that $27.5 \%$ of patients primarily diagnosed with BDD have comorbid OCD, whereas $10.4 \%$ of patients primarily diagnosed with OCD have comorbid $\operatorname{BDD}(6,7)$. Although OCD and BDD are presumably related to each other regarding underlying psychological and pathophysiological mechanisms, and grouped together in the Obsessive-Compulsive and Related Disorders chapter of the DSM-5 (8); evidence supporting this nosological approach requires comparative studies between BDD and OCD.

Dysfunctional connectivity in fronto-striatal networks is implicated in both OCD and BDD and overlaps with networks responsible for executive functions $(\mathrm{EF})(9,10)$. The function of these neural circuits can be assessed by specific psychometric tests $(11,12)$. Spatial working memory captures our ability to retain and organize visuospatial information, which involves frontoparietal circuitries $(13,14)$. Attentional set shifting, which is the ability to switch focus, is a form of cognitive flexibility that depends on the function of ventrolateral prefrontal cortex (15). Response inhibition, a measure of impulsivity, measured in the present study with the Stop Signal Task, is dependent on the inferior frontal cortex and its subcortical connections (11).

Studies using computer-standardized and validated neuropsychological tests such as the Cambridge Neuropsychological Test Automated Battery (CANTAB) have been used to assess important aspects of EF in patients with OCD and BDD. Three studies found that patients with OCD perform worse on the Spatial working memory task (SWM) compared with healthy controls and one additional study suggests that there could be a sex difference in task performance among patients with OCD (16-19). Similarly, Dunai et al. found worse performance on the SWM in patients with BDD compared with healthy controls (20). Worse performance on the Intra- extra dimensional set shifting (IED) in patients with OCD has been reported by Nedeljkovics et al., Watkins et al. Purcell et al., and Chamberlain et al. (16, 21-23), but not replicated by Purcell et al., Nielen et al., Veale et al., and Purcell et al. (17, 24, 25). Both Jefferies-Sewell et al., and Greenberg et al., showed that patients with BDD performed poorer on IED 
medRxiv preprint doi: https://doi.org/10.1101/2021.04.29.21256321; this version posted May 2, 2021. The copyright holder for this preprint (which was not certified by peer review) is the author/funder, who has granted medRxiv a license to display the preprint in perpetuity. All rights reserved. No reuse allowed without permission.

compared with healthy controls $(26,27)$. Stop signal task (SST) has been found to be deficient in patients with OCD in several studies $(11,18,23,28-31)$, but recent findings by Kalanthroff et al. could not demonstrate any difference, independent of medication status (32). Similarly, Jefferies-Sewell et al. showed worse test performance on the SST among patients with BDD in comparison to healthy controls (27). In summary, these studies suggest that similar EF could be deficient in patients with OCD and $\mathrm{BDD}$, however, the results are inconclusive for OCD and scarce for BDD.

Direct comparisons between patients with OCD and BDD on EF are scarce. A study that compared 14 patients with BDD to 23 patients with OCD from previously published data detected similar, but not equivalent task performance on spatial span, spatial working memory, executive planning and pattern recognition (33). Another study showed poorer test performance on executive planning and the Stroop test between 14 patients with BDD and 10 patients with OCD compared to healthy controls (34). The question whether patients with OCD and BDD patients have similar or separate EF has important implications, since knowledge about neurocognitive performance in OCD and BDD could improve our neurobiological understanding and facilitate classification of these disorders, uncovering potentially important predictors of treatment outcome, and inform clinical care for these patients.

The aim of this study was therefore to use CANTAB to compare EF (spatial working memory, set shifting and response inhibition) between patients with OCD, BDD, and healthy controls. We hypothesized that OCD and BDD would exhibit similar executive dysfunction compared with healthy controls. Furthermore, we hypothesized that higher burden of symptoms is correlated with poorer EF among patients with OCD and BDD.

\section{METHODS}

\section{Participants}

Patients with OCD $(n=29)$ were recruited from two psychiatric outpatient clinics in Stockholm specialized in obsessive-compulsive and related disorders. Patients with BDD $(n=26)$ were participants in two studies on internet-delivered cognitive behavior therapy for BDD, conducted at Karolinska Institutet $(35,36)$. Inclusion criteria were a principal diagnosis of OCD or BDD according to the Diagnostic and Statistical Manual of Mental Disorders, fifth edition (DSM-5) (8). Exclusion criteria were i) psychotropic medication changes within at least two weeks prior to inclusion ii) completed cognitive behavioral therapy for OCD or BDD within the last 12 months, iii) comorbid OCD or BDD respectively, iv) current substance dependence or abuse, v) bipolar disorder, vi) psychotic disorders, vii) acute suicidal ideation, viii) severe personality disorder and ix) concurrent psychological treatment. 
medRxiv preprint doi: https://doi.org/10.1101/2021.04.29.21256321; this version posted May 2, 2021. The copyright holder for this preprint (which was not certified by peer review) is the author/funder, who has granted medRxiv a license to display the preprint in perpetuity. All rights reserved. No reuse allowed without permission.

Healthy controls $(n=28)$ similar in age, sex and education, were recruited by online advertisement in the greater Stockholm catchment area. Exclusion criteria for healthy controls consisted of previous or present psychiatric disorder, psychotropic medication or chronic somatic disease. All participants were screened for eligibility and subsequently underwent a diagnostic interview using Mini International Neuropsychiatric Interview (M.I.N.I) and Structured clinical interview (SCID) with an experienced psychologist or psychiatrist before inclusion.

\section{Ethics}

The regional ethical review board in Stockholm approved the study (registration ID 2015/1088-32 and 2013/1773-31/4). All trial subjects gave their written consent prior to participation in the study which adheres to the Declaration of Helsinki.

\section{Psychometric scales}

Symptom severity of patients was assessed using the Yale-Brown Obsessive Compulsive Scale (YBOCS) for OCD or the modified version (BDD-YBOCS) for BDD $(37,38)$. Depressive symptoms were assessed with the self-rated version of the Montgomery-Åsberg Depression Rating Scale (MADRS-S) (39). The National Adult Reading Test, NART-SWE, was administered to all participants. NART-SWE is a validated test with sufficient reliability for assessment of premorbid IQ (40).

\section{Neurocognitive tests}

Three tests from the Cambridge Neuropsychological Test Automated Battery (CANTAB) were administered in a fixed order and in a quiet room with a trained administrator giving standardized instructions. The tests were chosen to assess neurocognitive abilities of the participants, and key outcome measures for each test are presented below:

Spatial working memory (SWM) measures the ability to retain and systematically organize visuospatial information (41). Participants are instructed to search for blue tokens hidden inside colored squares on the screen. Four levels of difficulty: three, four, six or eight boxes are presented at the same time. Two outcome measures are obtained. A between-search error means revisiting boxes in which a token has already been found. Strategy scores reflect how often search sequences are initiated from the same box within a trial.

Intra- extra dimensional set shifting (IED) measures cognitive flexibility and specifically the ability to shift attention from irrelevant to relevant stimuli (42). Study subjects are asked to choose the right figure from two artificial dimensions with two figures each. Through trial and error, the rule of the game can be acquired. The rule changes after each block and at block eight the previously relevant dimension becomes irrelevant and vice versa. This is called the extra-dimensional shift, a measure of 
medRxiv preprint doi: https://doi.org/10.1101/2021.04.29.21256321; this version posted May 2, 2021. The copyright holder for this preprint (which was not certified by peer review) is the author/funder, who has granted medRxiv a license to display the preprint in perpetuity. All rights reserved. No reuse allowed without permission.

reversal learning. Outcome measures of interest include number of stages completed, total number of errors and number of errors in the extra dimensional shift.

The Stop Signal Task (SST) measures response inhibition (43). Left and right arrows are presented randomly on a screen and participants are asked to press the corresponding button as fast as possible (go trial). However, participants are instructed to inhibit the response of pressing a button if an auditory signal is given, which occurs after an arrow is shown (no-go trial). The main outcome variable, Stop Signal Reaction Time (SSRT), is the mean time in milliseconds (ms) taken by the participant to suppress a prepotent response. The average reaction time for 'go' trials (i.e., trials without a stop signal) is a measure of a subject's reaction time (psychomotor speed).

\section{Statistical analysis}

Baseline demographic differences (age, sex, education, IQ, depressive symptoms and medication status) are presented as summary statistics, and between-group differences were tested using ANOVA for continuous variables and chi square for ordinal variables. Multiple linear regression models, controlled for age, sex, NART-SWE score and MADRS-S depressive symptoms, were used to compare test performance between the groups. Standardized effect sizes (Cohen's $d$ ) were obtained by dividing the estimated marginal means by the residual degrees of freedom from the regression model described above, using the standard deviation of the model residuals as sigma (population standard deviation) as implemented in the emmeans $\mathrm{R}$ package (44). For the two clinical groups, symptom severity scores (Y-BOCS and BDD-YBOCS, respectively) were standardized and compared to test performance using main diagnosis as covariate. Pearson's $r$ was used as a measure of effect size. The linear models were deemed appropriate for the data by inspecting residuals, homoscedasticity and outliers using diagnostic plots. Missing values ( $<10 \%$ for all variables) were assumed to be missing at random (MAR) and were imputed using bagged trees, a non-linear ensemble method that can impute both continuous and categorical data. In bagged trees imputation, each missing value is predicted in bootstrap resampling of data and aggregated to form a single prediction using averages for continuous values and majority vote for categorical outcomes. Regular bagged trees allow for non-linear ensemble imputation whereby all predictors are available, and the best one is selected, at each decision node split for each tree in the ensemble $(45,46)$. All statistical analyses were performed using R version 4.0.2 and STATA version 15 (StataCorp: College Station)(47). Code for the statistical analyses is available on the Open Science Framework (https://doi.org/10.17605/OSF.IO/63YNF). 
medRxiv preprint doi: https://doi.org/10.1101/2021.04.29.21256321; this version posted May 2, 2021. The copyright holder for this preprint (which was not certified by peer review) is the author/funder, who has granted medRxiv a license to display the preprint in perpetuity.

All rights reserved. No reuse allowed without permission.

\section{RESULTS}

\section{Demographic and clinical characteristics}

In the present sample, groups did not differ in age, sex, or highest completed education (Table 1). The proportion of patients on SSRI was higher in the OCD group compared with the BDD group, and patients with OCD had lower NART-SWE premorbid IQ. Moreover, OCD and BDD groups scored higher on depressive symptoms compared to healthy controls. On average, symptom severity was in the moderate-to-severe range for OCD and BDD groups. See Table 1 for demographic and clinical characteristics of the participants.

\section{Table 1}

Sociodemographic and clinical characteristics of participants with Obsessive-compulsive disorder, Body Dysmorphic disorder and healthy controls

\begin{tabular}{|c|c|c|c|c|}
\hline Demographic variables, $\mathrm{n}(\%)$ & Control $(\mathrm{n}=28)$ & OCD $(n=29)$ & $\operatorname{BDD}(n=26)$ & Missing values, $\mathrm{n}(\%)$ \\
\hline Age, Mean (SD) & $30.8(11.9)$ & $31.2(9.2)$ & $30.7(9.5)$ & $1(1 \%)$ \\
\hline Sex; Female count $(\%)$ & $19(68 \%)$ & $15(52 \%)$ & $18(70 \%)$ & $1(1 \%)$ \\
\hline Highest completed education; \% & & & & 0 \\
\hline Primary school & $1(3.6 \%)$ & $2(6.9 \%)$ & 0 & \\
\hline Vocational school & $1(3.6 \%)$ & $2(6.9 \%)$ & 0 & \\
\hline High school & $16(57 \%)$ & $14(48.2 \%)$ & $18(69.2 \%)$ & \\
\hline University degree & $10(35.7 \%)$ & $10(34.5 \%)$ & $7(26.9 \%)$ & \\
\hline Ph.D & 0 & $1(3.4 \%)$ & $1(3.85 \%)$ & \\
\hline NART-SWE & $37.9(5.0)$ & $33.4(5.8) *$ & $37.7(5.8)$ & $3(4 \%)$ \\
\hline MADRS score (0-56), mean (SD) & $2.8(2.6)$ & $21.4(8.8) *$ & $17.1(8.0) *$ & $1(1 \%)$ \\
\hline \multicolumn{5}{|c|}{ Clinical variables (OCD \& BDD group only) } \\
\hline YBOCS score, mean, (SD) & & $24.9(5.2)$ & N/A & 0 \\
\hline BDD-YBOCS score, mean (SD) & & N/A & $29,4(5,4)$ & 0 \\
\hline SSRI medication & & $23(79 \%) *$ & $5(19 \%) *$ & 0 \\
\hline Comorbid conditions & & & & $5(9 \%)$ \\
\hline Depression & & $10(37 \%)$ & $13(57 \%)$ & \\
\hline Social phobia & & $2(7 \%)$ & $5(22 \%)$ & \\
\hline Panic disorder & & $2(7 \%)$ & $1(4 \%)$ & \\
\hline Generalized anxiety disorder & & $2(7 \%)$ & $1(4 \%)$ & \\
\hline Bulimia nervosa & & 0 & $1(4 \%)$ & \\
\hline Tourette's syndrome & & $3(11 \%)$ & 0 & \\
\hline Trichotillomania & & $1(4 \%)$ & 0 & \\
\hline
\end{tabular}

OCD, Obsessive-compulsive disorder; BDD, Body dysmorphic disorder; Nart-Swe, National adult reading test- 
medRxiv preprint doi: https://doi.org/10.1101/2021.04.29.21256321; this version posted May 2, 2021. The copyright holder for this preprint (which was not certified by peer review) is the author/funder, who has granted medRxiv a license to display the preprint in perpetuity. All rights reserved. No reuse allowed without permission.

estimated verbal IQ in Swedish; MADRS, Montgomery-Åsberg Depression Rating Scale; Y-BOCS, Yale Brown

Obsessive Compulsive Scale; BDD-YBOCS, Yale Brown Obsessive Compulsive Scale for Body Dysmorphic

Disorder, SSRI, Selective serotonin receptor inhibitors. * P-value $<0.05$.

\section{Neurocognitive task performance}

Table 2 shows estimated means and standardized effect sizes across groups on the specific CANTAB tests.

Table 2

Estimated mean group differences on principal outcomes for Spatial working memory, Intra- extra dimensions set shifting and Stop signal task

Group, Estimated mean (SE) Group comparisons, Cohen's $d$ [95\%

confidence interval]

\begin{tabular}{lllll}
\hline Control & OCD & BDD & Control - & Control - \\
& & OCD & BDD - OCD \\
& & \\
\end{tabular}

Spatial Working Memory

Total between-

search errors

$15.22(4.28)$

$23.32(3.73)$

$21.4(3.40)$

$-0.51[-1.35$ to -0.3 $-0.39[-1.10$ to $-0.12[-0.73$ to

Strategy score

$$
30.06(1.54) \quad 31.47
$$

Total errors

$$
16.89(3.25)
$$

$17.47(2.58)$

$-0.35[-1.19$ to -0.0

$-0.05[-0.75$ to $-0.30[-0.91$ to

$$
0.49]
$$

$0.66]$

0.31]

Extra

dimensional

errors

$7.82(2.55)$

$10.11(2.23)$

$9.23(2.03)$
$-0.24[-1.08$ to $-0.15[-0.86$ to $-0.09[-0.70$ to $0.60]$
$0.56]$

\begin{tabular}{|c|c|c|c|c|c|c|}
\hline \\
\hline \multicolumn{7}{|c|}{$-0.07[-0.91$ to $-0.22[-0.93$ to $0.15[-0.46$ to } \\
\hline (ms) & $216.59(30.4)$ & $224.53(26.5)$ & $241.58(24.16)$ & 0.77] & $0.49]$ & $0.76]$ \\
\hline Mean reaction & 428.99 & & & $0.18[-0.66$ to & $-0.16[-0.87$ to & $0.34[-0.27$ to \\
\hline time $(\mathrm{ms})$ & (27.88) & $410.26(24.3)$ & $445.9(22.15)$ & $1.02]$ & $0.55]$ & $0.95]$ \\
\hline
\end{tabular}
$0.51]$

\section{Stop Signal Task}


medRxiv preprint doi: https://doi.org/10.1101/2021.04.29.21256321; this version posted May 2, 2021. The copyright holder for this preprint (which was not certified by peer review) is the author/funder, who has granted medRxiv a license to display the preprint in perpetuity. All rights reserved. No reuse allowed without permission.

Abbreviations: BDD, Body Dysmorphic disorder; OCD, Obsessive-compulsive disorder; SE, standard error.

Estimated marginal means based on the linear models using age, sex, language score and depressive symptoms as covariates.

\section{Spatial working memory}

There were no statistically significant differences in SWM strategy score when comparing the OCD group $($ Estimate $=1.41[95 \% \mathrm{CI}-3.42$ to 6.24$], \mathrm{SE}=2.43, p=0.56)$ and BDD group $($ Estimate $=1.84$ [95\% CI -2.24 to 5.92], $\mathrm{SE}=2.05, p=0.37$ ) to healthy controls. Further, there were no statistically significant main effects of age, sex, NART-SWE score, or MADRS-S score.

Similarly, for the SWM between errors estimates for each group, there were no statistically significant differences between the OCD group (Estimate $=8.11$ [95\% CI -5.30 to 21.52], $\mathrm{SE}=6.74, p=0.23$ ) and BDD group (Estimate $=6.18$ [95\% CI -5.14 to 17.50], $\mathrm{SE}=5.68, p=0.28$ ). There was, however, a small but statistically significant main effect of age (Estimate $=0.41$ [95\% CI 0.04 to 0.78], $\mathrm{SE}=0.19$, $p=0.03$ ) showing an association between higher age and a higher SWM between errors score.

\section{Intra- extra dimensional set shifting}

All participants in the groups passed stages 1-7. Twenty-four percent $(n=7)$ of the OCD group failed to pass the extra-dimensional shift stage (EDS stage, stage 8) compared to 19\% $(n=5)$ in the BDD group and $10 \%(\mathrm{n}=3)$ of the control subjects. Neither the OCD group (Estimate $=4.23$ [95\% CI -5.97 to 14.43], $\mathrm{SE}=5.12, p=0.41$ ) nor the BDD group (Estimate $=0.57$ [95\% CI -8.04 to 9.18], $\mathrm{SE}=4.32, p$ $=0.89$ ) differed from the control group in total IED errors, however there was a statistically significant effect of sex where women had a higher mean than men (Estimate $=6.11$ [95\% CI 0.32 to 11.90], SE $=$ 2.91, $p=0.04)$.

Extra-dimensional shift errors were similar with no differences between the OCD $($ Estimate $=2.29$ [95\% CI -5.72 to 10.30], $\mathrm{SE}=4.02, p=0.57)$ and $\mathrm{BDD}($ Estimate $=1.41$ [95\% CI -5.35 to 8.17], $\mathrm{SE}=$ $3.40, p=0.68$ ) groups compared to healthy controls, but a statistically significant effect of sex where females scored higher $($ Estimate $=8.64[95 \%$ CI 4.10 to 13.19$], \mathrm{SE}=2.28, p<0.001$ ).

\section{Stop signal task}

The difference in Stop signal reaction time did not differ between the OCD (Estimate $=7.94$ [95\% CI 87.41 to 103.29], $\mathrm{SE}=47.88, p=0.87$ ) and $\mathrm{BDD}$ (Estimate $=24.99$ [95\% CI -55.50 to 105.48], $\mathrm{SE}=$ $40.42, p=0.54$ ) groups compared to healthy controls, and there were no statistically significant associations with other covariates.

Similarly, the mean reaction time did not differ between the OCD group (Estimate $=-18.72$ [95\% CI 106.16 to 68.71$], \mathrm{SE}=43.91, p=0.67)$ and the BDD group (Estimate $=16.91$ [95\% CI -56.89 to 
medRxiv preprint doi: https://doi.org/10.1101/2021.04.29.21256321; this version posted May 2, 2021. The copyright holder for this preprint (which was not certified by peer review) is the author/funder, who has granted medRxiv a license to display the preprint in perpetuity. All rights reserved. No reuse allowed without permission.

90.72], $\mathrm{SE}=37.07, p=0.65)$ compared to healthy controls, however there was a statistically significant main effect of age (Estimate $=3.06$ [95\% CI 0.64 to 5.47], $\mathrm{SE}=1.21, p=0.01$ ) where a higher age was associated with a longer average reaction time.

\section{Symptom severity and neurocognitive task performance}

In a subgroup analysis of the patients with OCD and BDD we investigated a standardized symptom severity score based on the Y-BOCS and BDD-YBOCS total scores, respectively, as well as group. Figure 1 displays the correlations between symptom severity and neurocognitive task performance.

\section{Spatial working memory}

Symptom severity was statistically significantly associated with SWM strategy (Estimate $=1.80$ [95\% CI 0.22 to 3.78], $\mathrm{SE}=0.79, p=0.03$ ), and there was a positive but not statistically significant correlation between symptom severity and SWM strategy score (OCD: $r=0.35, p=0.066$; BDD: $r=$ $0.26, p=0.206)$.

The model for SWM between errors showed an association between symptom severity and test performance (Estimate $=5.64$ [95\% CI 0.95 to 10.33], $\mathrm{SE}=2.41, p=0.02$ ), which was also seen in the correlation between symptom severity and test performance in the OCD $(r=0.31, p=0.102)$ and BDD $(r=0.33, p=0.099)$ groups.

\section{Intra- extra dimensional set shifting}

There was no statistically significant association between symptom severity and intra- extra dimensional total errors (Estimate $=2.76$ [95\% CI -0.76 to 6.28], $\mathrm{SE}=1.75, p=0.12$ ), with weak correlations between symptom severity and performance in both the OCD $(r=0.22, p=0.253)$ and BDD $(r=0.21$, $p=0.311$ ) groups.

Similar results were found in the analysis of extra dimensional errors, with no statistically significant association between symptom severity (Estimate $=2.37$ [95\% CI -0.62 to 5.36], $\mathrm{SE}=1.59, p=0.12$ ), and weak correlations in both groups (OCD: $r=0.26, p=0.177$; BDD: $r=0.17, p=0.416$ ).

\section{Stop signal task}

The model for Stop signal reaction time indicated a statistically significant association between symptom severity and task performance (Estimate $=-46.31$ [95\% CI -78.69 to -13.95$], \mathrm{SE}=16.13, p=$ 0.005), and correlations differed between the groups with a statistically significant correlation in patients with $\operatorname{BDD}(r=-0.49, p=0.01)$ but not in patients with $\mathrm{OCD}(r=-0.22, p=0.247)$. When analyzing mean reaction time, there was an effect of symptom severity (Estimate $=-35.76[95 \%$ $\mathrm{CI}-64.49$ to -7.04$], \mathrm{SE}=14.31, p=0.02)$ and a moderate negative correlation between symptom severity and mean reaction time in patients with $\operatorname{BDD}(r=-0.5, p=0.009)$ but not $\operatorname{OCD}(r=-0.094, p=$ $0.629)$. 
medRxiv preprint doi: https://doi.org/10.1101/2021.04.29.21256321; this version posted May 2, 2021. The copyright holder for this preprint (which was not certified by peer review) is the author/funder, who has granted medRxiv a license to display the preprint in perpetuity.

All rights reserved. No reuse allowed without permission.

\section{Figure 1.}

Linear associations between symptom severity and executive function in OCD and BDD clinical groups.

A

\section{SWM strategy}

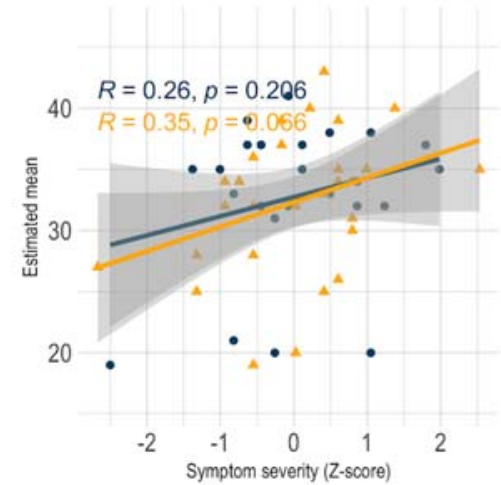

C

\section{IED total errors}

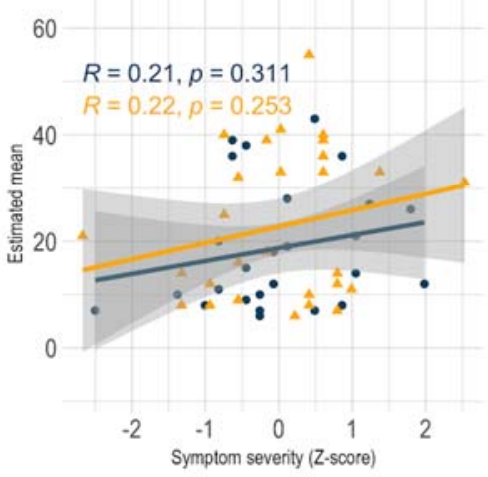

E

\section{SST stop-signal reaction time}

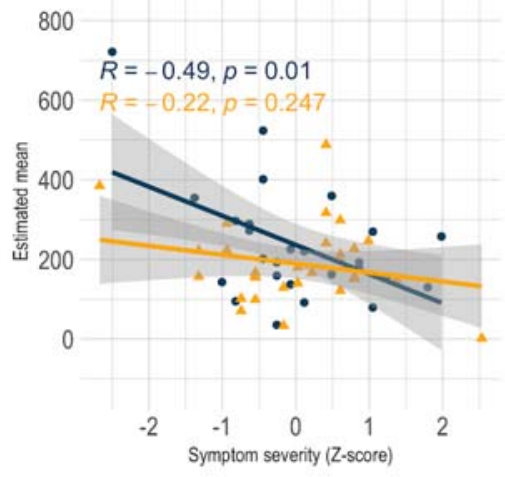

\section{SWM between errors}

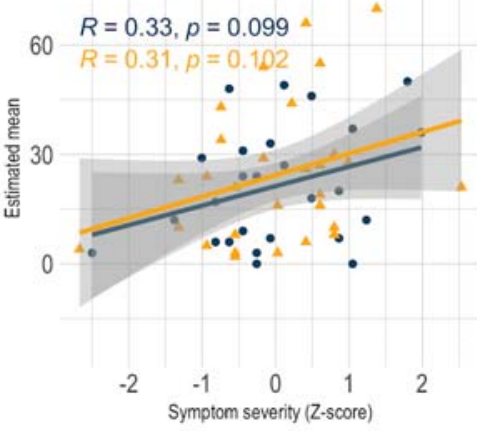

D

\section{IED extra-dimensional shift errors}

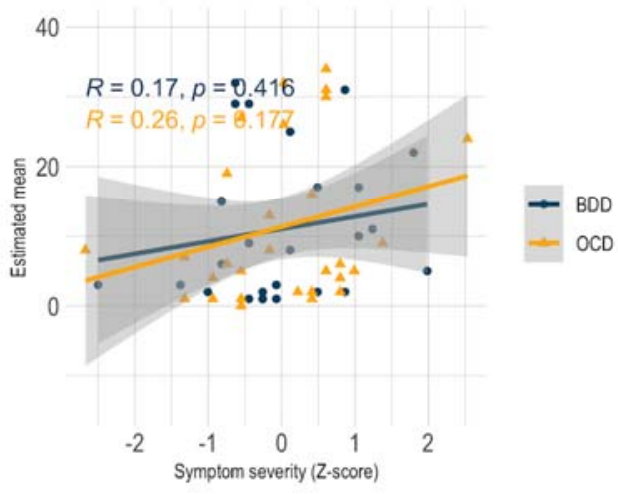

F

\section{SST mean reaction time}

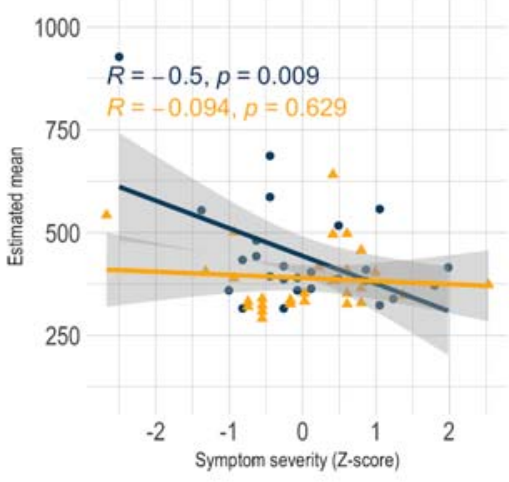


medRxiv preprint doi: https://doi.org/10.1101/2021.04.29.21256321; this version posted May 2, 2021. The copyright holder for this preprint (which was not certified by peer review) is the author/funder, who has granted medRxiv a license to display the preprint in perpetuity. All rights reserved. No reuse allowed without permission.

\section{Sensitivity analyses}

Results were attenuated but similar when adding age, sex, and SSRI medication status into the models. Both SWM strategy score (Estimate $=1.81$ [95\% CI 0.01 to 3.61], $\mathrm{SE}=0.90, p=0.05)$ and between errors (Estimate $=8.71$ [95\% CI 3.56 to 13.85$], \mathrm{SE}=2.56, p=0.001)$ showed an association with clinical symptoms. As in the main analysis, symptom severity showed a weak association to both IED total errors (Estimate $=2.37$ [95\% CI -1.73 to 6.47], $\mathrm{SE}=2.04, p=0.25$ ) and IED extra dimensional errors (Estimate $=0.84$ [95\% CI -2.35 to 4.04], $\mathrm{SE}=1.59, p=0.60$ ). Finally, the estimates from the stop signal reaction time (Estimate $=-46.45[95 \% \mathrm{CI}-81.59$ to -11.31$], \mathrm{SE}=17.49, p=0.01$ ) and mean reaction time (Estimate $=-30.37$ [95\% CI -61.58 to 0.84$], \mathrm{SE}=15.53, p=0.06$ ) were similar but slightly weakened. Overall, associations between clinical symptoms and CANTAB test scores were in the same direction and of similar magnitude in the sensitivity analyses compared to main analyses.

\section{DISCUSSION}

In this study, we compared executive functions (EF) between patients with OCD, BDD and healthy controls using computerized and standardized tests. There were no statistically significant differences in group means for either of the three tests: Spatial working memory (SWM), Intra- extra dimensional setshifting (IED), and Stop signal task (SST). Age was found to be a covariate associated with performance on SWM and SST, whereas sex was associated with performance on IED. There were statistically significant associations between symptom severity and test performance in SWM between errors and the SST, but not for the IED task. The correlation coefficients indicated that higher symptom severity was associated with worse performance for both the BDD and OCD groups in SWM, but reverse correlation for the BDD group in the SST.

Our findings differ from previous studies in that the clinical groups did not perform significantly worse than healthy controls. One explanation could be that the clinical cases in previous studies were more severe than the present cases, yet this seems unlikely given that the present cases were regular psychiatry patients diagnosed, assessed and treated by gold standard procedure. Instead, comparing crude numbers on performance on IED and SST shows that patients with OCD and BDD in our study are comparable to those in previous studies, however, healthy controls perform much better in previous studies $(26,27)$. Recruiting healthy controls from universities constitutes a risk for selection bias, since university students may have prominent $\mathrm{EF}$ and are therefore not representative for the general population. In addition, OCD is a prevalent comorbidity in patients with BDD from previous studies, up to $75 \%$ of all participants in one study (27). The evidence for deficient EF in all three tests is more 
medRxiv preprint doi: https://doi.org/10.1101/2021.04.29.21256321; this version posted May 2, 2021. The copyright holder for this preprint (which was not certified by peer review) is the author/funder, who has granted medRxiv a license to display the preprint in perpetuity. All rights reserved. No reuse allowed without permission.

robust in patients with OCD compared with studies on $\operatorname{BDD}(48,49)$. Therefore, high comorbidity of $\mathrm{OCD}$ in a BDD population could be a major confounding factor when interpreting the results.

It has been suggested that certain executive dysfunctions, such as cognitive inflexibility and deficient response inhibition, constitute an increased risk for developing compulsive behaviors, due to inadequate habit formations, inability to stop a response or sequence, and failure to maintain goal-directed behavior (50-52). Nevertheless, using neuropsychological tests to probe for specific EF is treacherous since EFs require multiple cognitive processes (53). Especially considering that comparability between studies is limited by the use of different neuropsychological tests, both manually administered and computerstandardized tests (54).

Even if patients with OCD and BDD had impaired EF in cognitive flexibility or response inhibition, other cognitive processes could compensate for substantial abnormalities, which has been suggested for IED and SST in patients with OCD (55-57). Moreover, major psychiatric disorders, such as attention deficit hyperactivity disorder, major depressive disorder, bipolar disorder, and schizophrenia, are associated with deficits in EF with similar or larger effect sizes (58-60). This is in line with metaanalyses of patients with OCD showing broad impairment in EF, but small to moderate effect sizes compared to healthy controls $(48,49,61)$. This raises the question whether specific executive dysfunctions are characteristic for patients with OCD and BDD or whether they exhibit nonspecific cognitive impairments.

Symptom severity was associated with worse performance on some, but not all, tasks in the CANTAB for both diagnostic groups. This is in line with previous literature, where results are inconsistent. Furthermore, methodological shortcomings from previous studies limits the generalizability of these findings (62). The lack of a clear association between symptom severity and neuropsychological testresults dampens expectations that results from neurocognitive tests can serve as markers of severity or predictors of treatment outcomes. However, impaired EF has been suggested to impact the outcome of cognitive behavioral therapy (63-65) and well powered longitudinal studies are warranted to further study these associations.

\section{Limitations}

Firstly, EF involve several higher-order cognitive processes and the tasks that participants have accomplished in this study assess important aspects of it. However, for comprehensive characterization of EF in patients with obsessive-compulsive and related disorders, other neuropsychological tests could be considered (66). Secondly, patients with OCD had significantly lower NART-SWE scores and used medication to a greater extent than patients with BDD or healthy controls, although previous studies do not suggest a correlation between IQ and EF $(27,28)$. Moreover, studies so far have not yielded convincing results that indicate significant interaction between serotonin reuptake inhibitor (SSRI) and cognitive 
medRxiv preprint doi: https://doi.org/10.1101/2021.04.29.21256321; this version posted May 2, 2021. The copyright holder for this preprint (which was not certified by peer review) is the author/funder, who has granted medRxiv a license to display the preprint in perpetuity. All rights reserved. No reuse allowed without permission.

functions $(24,32)$. Lastly, a small sample size can limit the power to detect significant differences (67). However, despite a comparable or larger sample size compared with previous studies, we did not see a generally deficient EF in patients with OCD or BDD.

\section{Conclusion}

Patients with OCD, BDD, and healthy controls performed comparably on neuropsychological tests assessing EF, tentatively suggesting that EF in spatial working memory, cognitive flexibility and response inhibition are similar on a group level. There were associations between symptom severity and test performance on some, but not all, neurocognitive tests for the participants with OCD and BDD, generally indicating worse performance with higher symptom severity. A larger sample size might be needed to determine the presence or absence of group differences in EF with more certainty, especially in patients with BDD. Moreover, longitudinal studies may reveal the clinical relevance of neuropsychological test performance for prognosis and treatment outcome.

\section{Funding}

This work was supported by Fredrik O Ingrid Thurings stiftelse (2018-00388), Chen and SöderströmKönig Foundation (SLS-941192), Wallert.

\section{Disclosures}

None of the authors report any additional financial or other relationships that poses a conflict of interest. 
medRxiv preprint doi: https://doi.org/10.1101/2021.04.29.21256321; this version posted May 2, 2021. The copyright holder for this preprint (which was not certified by peer review) is the author/funder, who has granted medRxiv a license to display the preprint in perpetuity. All rights reserved. No reuse allowed without permission.

\section{References}

1. Phillips KA, Stein DJ, Rauch SL, Hollander E, Fallon BA, Barsky A, et al. Should an obsessivecompulsive spectrum grouping of disorders be included in DSM-V? Depress Anxiety. 2010;27(6):528-55.

2. Heyman I, Mataix-Cols D, Fineberg NA.

Obsessive-compulsive disorder. Bmj. 2006;333(7565):424-9.

3. Grant JE, Phillips KA. Recognizing and treating body dysmorphic disorder. Ann Clin Psychiatry. 2005;17(4):205-10.

4. Koran LM, Abujaoude E, Large MD, Serpe RT. The prevalence of body dysmorphic disorder in the United States adult population. CNS Spectr.

2008;13(4):316-22.

5. Monzani $B$, Rijsdijk F, lervolino AC, Anson $M$, Cherkas L, Mataix-Cols D. Evidence for a genetic overlap between body dysmorphic concerns and obsessivecompulsive symptoms in an adult female community twin sample. Am J Med Genet B Neuropsychiatr Genet. 2012;159b(4):376-82.

6. Frías Á, Palma C, Farriols N, González L.

Comorbidity between obsessive-compulsive disorder and body dysmorphic disorder: prevalence, explanatory theories, and clinical characterization. Neuropsychiatr Dis Treat. 2015;11:2233-44.

7. Monzani B, Rijsdijk F, Harris J, Mataix-Cols D.

The structure of genetic and environmental risk factors for dimensional representations of DSM-5 obsessivecompulsive spectrum disorders. JAMA Psychiatry. 2014;71(2):182-9.

8. Association AP. Diagnostic and statistical manual of mental disorders (DSM- $5^{\circledR}$ ): American

Psychiatric Pub; 2013.
9. Menzies L, Chamberlain SR, Laird AR, Thelen SM, Sahakian BJ, Bullmore ET. Integrating evidence from neuroimaging and neuropsychological studies of obsessive-compulsive disorder: the orbitofronto-striatal model revisited. Neurosci Biobehav Rev. 2008;32(3):52549.

10. Beucke JC, Sepulcre J, Buhlmann U, Kathmann N, Moody T, Feusner JD. Degree connectivity in body dysmorphic disorder and relationships with obsessive and compulsive symptoms. Eur Neuropsychopharmacol. 2016;26(10):1657-66.

11. Menzies L, Achard S, Chamberlain SR, Fineberg

$\mathrm{N}$, Chen $\mathrm{CH}$, del Campo $\mathrm{N}$, et al. Neurocognitive endophenotypes of obsessive-compulsive disorder. Brain. 2007;130(Pt 12):3223-36.

12. Lezak MD. Neuropsychological assessment, 3rd ed. New York, NY, US: Oxford University Press; 1995. xviii, 1026-xviii, p.

13. McAfoose J, Baune BT. Exploring visual-spatial working memory: a critical review of concepts and models. Neuropsychol Rev. 2009;19(1):130-42.

14. Owen AM, McMillan KM, Laird AR, Bullmore E. $\mathrm{N}$-back working memory paradigm: a meta-analysis of normative functional neuroimaging studies. Hum Brain Mapp. 2005;25(1):46-59.

15. Hampshire A, Owen AM. Fractionating attentional control using event-related $\mathrm{fMRI}$. Cereb Cortex. 2006;16(12):1679-89.

16. Purcell R, Maruff $P$, Kyrios $M$, Pantelis $C$. Cognitive deficits in obsessive-compulsive disorder on tests of frontal-striatal function. Biol Psychiatry. 1998;43(5):348-57.

17. Purcell R, Maruff $P$, Kyrios $M$, Pantelis C. Neuropsychological deficits in obsessive-compulsive 
medRxiv preprint doi: https://doi.org/10.1101/2021.04.29.21256321; this version posted May 2, 2021. The copyright holder for this preprint (which was not certified by peer review) is the author/funder, who has granted medRxiv a license to display the preprint in perpetuity. All rights reserved. No reuse allowed without permission.

disorder: a comparison with unipolar depression, panic disorder, and normal controls. Arch Gen Psychiatry. 1998;55(5):415-23.

18. Chamberlain SR, Fineberg NA, Blackwell AD, Clark L, Robbins TW, Sahakian BJ. A neuropsychological comparison of obsessive-compulsive disorder and trichotillomania. Neuropsychologia. 2007;45(4):654-62.

19. Martoni RM, Salgari G, Galimberti E, Cavallini

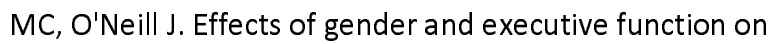
visuospatial working memory in adult obsessivecompulsive disorder. Eur Arch Psychiatry Clin Neurosci. 2015;265(8):707-18.

20. Dunai J, Labuschagne I, Castle DJ, Kyrios $M$, Rossell SL. Executive function in body dysmorphic disorder. Psychol Med. 2010;40(9):1541-8.

21. Nedeljkovic M, Kyrios M, Moulding R, Doron G, Wainwright $\mathrm{K}$, Pantelis $\mathrm{C}$, et al. Differences in neuropsychological performance between subtypes of obsessive-compulsive disorder. Aust N Z J Psychiatry. 2009;43(3):216-26.

22. Watkins LH, Sahakian BJ, Robertson MM, Veale DM, Rogers RD, Pickard KM, et al. Executive function in Tourette's syndrome and obsessive-compulsive disorder. Psychol Med. 2005;35(4):571-82.

23. Chamberlain SR, Fineberg NA, Menzies LA, Blackwell AD, Bullmore ET, Robbins TW, et al. Impaired cognitive flexibility and motor inhibition in unaffected first-degree relatives of patients with obsessivecompulsive disorder. Am J Psychiatry. 2007;164(2):335-8.

24. Nielen MM, Den Boer JA. Neuropsychological performance of OCD patients before and after treatment with fluoxetine: evidence for persistent cognitive deficits. Psychol Med. 2003;33(5):917-25.

25. Veale DM, Sahakian BJ, Owen AM, Marks IM. Specific cognitive deficits in tests sensitive to frontal lobe dysfunction in obsessive-compulsive disorder. Psychol Med. 1996;26(6):1261-9.

26. Greenberg JL, Weingarden $\mathrm{H}$, Reuman L, Abrams D, Mothi SS, Wilhelm S. Set shifting and visuospatial organization deficits in body dysmorphic disorder. Psychiatry Res. 2018;260:182-6.

27. Jefferies-Sewell K, Chamberlain SR, Fineberg NA, Laws KR. Cognitive dysfunction in body dysmorphic disorder: new implications for nosological systems and neurobiological models. CNS Spectr. 2017;22(1):51-60. 28. Boisseau CL, Thompson-Brenner H, CaldwellHarris C, Pratt E, Farchione T, Barlow DH. Behavioral and cognitive impulsivity in obsessive-compulsive disorder and eating disorders. Psychiatry Res. 2012;200(23):1062-6.

29. Penadés R, Catalán R, Rubia K, Andrés S, Salamero M, Gastó C. Impaired response inhibition in obsessive compulsive disorder. Eur Psychiatry. 2007;22(6):404-10.

30. Sohn SY, Kang JI, Namkoong K, Kim SJ. Multidimensional measures of impulsivity in obsessivecompulsive disorder: cannot wait and stop. PLoS One. 2014;9(11):e111739.

31. Lei H, Zhu X, Fan J, Dong J, Zhou C, Zhang X, et al. Is impaired response inhibition independent of symptom dimensions in obsessive-compulsive disorder? Evidence from ERPs. Sci Rep. 2015;5:10413.

32. Kalanthroff $E$, Teichert $T$, Wheaton MG, Kimeldorf MB, Linkovski O, Ahmari SE, et al. The Role of Response Inhibition in Medicated and Unmedicated Obsessive-Compulsive Disorder Patients: Evidence from the Stop-Signal Task. Depress Anxiety. 2017;34(3):301-6. 33. Labuschagne I, Rossell SL, Dunai J, Castle DJ, Kyrios M. A comparison of executive function in Body Dysmorphic Disorder (BDD) and Obsessive-Compulsive Disorder (OCD). Journal of Obsessive-Compulsive and Related Disorders. 2013;2(3):257-62.

34. Hanes KR. Neuropsychological performance in body dysmorphic disorder. J Int Neuropsychol Soc. 1998;4(2):167-71.

35. Enander J, Andersson E, Mataix-Cols D, Lichtenstein L, Alström K, Andersson $G$, et al. Therapist guided internet based cognitive behavioural therapy for 
medRxiv preprint doi: https://doi.org/10.1101/2021.04.29.21256321; this version posted May 2, 2021. The copyright holder for this preprint (which was not certified by peer review) is the author/funder, who has granted medRxiv a license to display the preprint in perpetuity. All rights reserved. No reuse allowed without permission.

body dysmorphic disorder: single blind randomised controlled trial. Bmj. 2016;352:i241.

36. Enander J, Ivanov VZ, Andersson E, Mataix-Cols D, Ljótsson B, Rück C. Therapist-guided, Internet-based cognitive-behavioural therapy for body dysmorphic disorder (BDD-NET): a feasibility study. BMJ Open. 2014;4(9):e005923.

37. Goodman WK, Price LH, Rasmussen SA, Mazure C, Fleischmann RL, Hill CL, et al. The Yale-Brown Obsessive Compulsive Scale. I. Development, use, and reliability. Arch Gen Psychiatry. 1989;46(11):1006-11.

38. Phillips KA, Hollander E, Rasmussen SA, Aronowitz BR, DeCaria C, Goodman WK. A severity rating scale for body dysmorphic disorder: development, reliability, and validity of a modified version of the YaleBrown Obsessive Compulsive Scale. Psychopharmacol Bull. 1997;33(1):17-22.

39. Svanborg P, Asberg M. A new self-rating scale for depression and anxiety states based on the Comprehensive Psychopathological Rating Scale. Acta Psychiatr Scand. 1994;89(1):21-8.

40. Rolstad S, Nordlund A, Gustavsson $\mathrm{MH}$, Eckerström C, Klang O, Hansen S, et al. The Swedish National Adult Reading Test (NART-SWE): a test of premorbid IQ. Scand J Psychol. 2008;49(6):577-82.

41. Harkin B, Kessler K. The role of working memory in compulsive checking and OCD: a systematic classification of 58 experimental findings. Clin Psychol Rev. 2011;31(6):1004-21.

42. Robbins TW, James M, Owen AM, Sahakian BJ, Lawrence $A D, M c l n n e s ~ L$, et al. A study of performance on tests from the CANTAB battery sensitive to frontal lobe dysfunction in a large sample of normal volunteers: implications for theories of executive functioning and cognitive aging. Cambridge Neuropsychological Test Automated Battery. J Int Neuropsychol Soc. 1998;4(5):474-90.

43. Logan GD, Cowan WB, Davis KA. On the ability to inhibit simple and choice reaction time responses: a model and a method. J Exp Psychol Hum Percept Perform. 1984;10(2):276-91.

44. Lenth R, Singmann H, Love J, Buerkner $P$, Herve M. Emmeans: Estimated marginal means, aka leastsquares means. $\mathrm{R}$ package version. 2018;1(1):3.

45. Cevallos Valdiviezo H, Van Aelst S. Tree-based prediction on incomplete data using imputation or surrogate decisions. Information Sciences. 2015;311:16381.

46. Kuhn M, Johnson K. Applied predictive modeling: Springer; 2013.

47. Team RC. R: A language and environment for statistical computing (3.5.1)[Computer software]. $R$ Foundation for Statistical Computing. 2020.

48. Shin NY, Lee TY, Kim E, Kwon JS. Cognitive functioning in obsessive-compulsive disorder: a metaanalysis. Psychol Med. 2014;44(6):1121-30.

49. Abramovitch A, Abramowitz JS, Mittelman A. The neuropsychology of adult obsessive-compulsive disorder: a meta-analysis. Clin Psychol Rev.

2013;33(8):1163-71.

50. Chamberlain SR, Menzies L. Endophenotypes of obsessive-compulsive disorder: rationale, evidence and future potential. Expert Rev Neurother. 2009;9(8):113346.

51. Gillan CM, Papmeyer M, Morein-Zamir S, Sahakian BJ, Fineberg NA, Robbins TW, et al. Disruption in the balance between goal-directed behavior and habit learning in obsessive-compulsive disorder. Am J Psychiatry. 2011;168(7):718-26.

52. Kashyap H, Fontenelle LF, Miguel EC, Ferrão YA, Torres AR, Shavitt RG, et al. 'Impulsive compulsivity' in obsessive-compulsive disorder: a phenotypic marker of patients with poor clinical outcome. J Psychiatr Res. 2012;46(9):1146-52.

53. Gruner P, Pittenger $C$. Cognitive inflexibility in Obsessive-Compulsive Disorder. Neuroscience. 2017;345:243-55.

54. Abramovitch A, Mittelman A, Tankersley AP, Abramowitz JS, Schweiger A. Neuropsychological 
medRxiv preprint doi: https://doi.org/10.1101/2021.04.29.21256321; this version posted May 2, 2021. The copyright holder for this preprint (which was not certified by peer review) is the author/funder, who has granted medRxiv a license to display the preprint in perpetuity. All rights reserved. No reuse allowed without permission.

investigations in obsessive-compulsive disorder: A

systematic review of methodological challenges.

Psychiatry Res. 2015;228(1):112-20.

55. Deckersbach T, Savage CR, Curran T, Bohne A,

Wilhelm S, Baer L, et al. A study of parallel implicit and

explicit information processing in patients with

obsessive-compulsive disorder. Am J Psychiatry.

2002;159(10):1780-2.

56. de Wit SJ, de Vries FE, van der Werf YD, Cath

DC, Heslenfeld DJ, Veltman EM, et al. Presupplementary motor area hyperactivity during response inhibition: a candidate endophenotype of obsessive-compulsive disorder. Am J Psychiatry. 2012;169(10):1100-8.

57. Remijnse PL, Nielen MM, van Balkom AJ, Cath DC, van Oppen P, Uylings HB, et al. Reduced orbitofrontal-striatal activity on a reversal learning task in obsessive-compulsive disorder. Arch Gen Psychiatry. 2006;63(11):1225-36.

58. Mesholam-Gately RI, Giuliano AJ, Goff KP, Faraone SV, Seidman LJ. Neurocognition in first-episode schizophrenia: a meta-analytic review. Neuropsychology. 2009;23(3):315-36.

59. Walshaw PD, Alloy LB, Sabb FW. Executive function in pediatric bipolar disorder and attentiondeficit hyperactivity disorder: in search of distinct phenotypic profiles. Neuropsychol Rev. 2010;20(1):103-

20.

60. Mann-Wrobel MC, Carreno JT, Dickinson D. Meta-analysis of neuropsychological functioning in euthymic bipolar disorder: an update and investigation of moderator variables. Bipolar Disord. 2011;13(4):334-

42.

61. Snyder HR, Kaiser RH, Warren SL, Heller W.

Obsessive-compulsive disorder is associated with broad impairments in executive function: A meta-analysis. Clin Psychol Sci. 2015;3(2):301-30.

62. Abramovitch A, McCormack B, Brunner D, Johnson $M$, Wofford $N$. The impact of symptom severity on cognitive function in obsessive-compulsive disorder: $A$ meta-analysis. Clin Psychol Rev. 2019;67:36-44.

63. Hybel KA, Mortensen EL, Lambek R, Højgaard D, Thomsen $\mathrm{PH}$. Executive function predicts cognitivebehavioral therapy response in childhood obsessivecompulsive disorder. Behav Res Ther. 2017;99:11-8.

64. Torp NC, Dahl K, Skarphedinsson G, Compton S, Thomsen PH, Weidle B, et al. Predictors associated with improved cognitive-behavioral therapy outcome in pediatric obsessive-compulsive disorder. J Am Acad Child Adolesc Psychiatry. 2015;54(3):200-7.e1.

65. Vandborg SK, Hartmann TB, Bennedsen BE, Pedersen AD, Thomsen PH. Can memory and executive functions in patients with obsessive-compulsive disorder predict outcome of cognitive behavioural therapy? Nord J Psychiatry. 2016;70(3):183-9.

66. Delis DC, Kaplan E, Kramer JH. Delis-Kaplan executive function system. 2001.

67. Button KS, loannidis JP, Mokrysz C, Nosek BA, Flint J, Robinson ES, et al. Power failure: why small sample size undermines the reliability of neuroscience. Nat Rev Neurosci. 2013;14(5):365-76. 